\title{
MEMORIAS FRAGMENTADAS DE LA DICTADURA \\ CHILENA: CONSTRUCCIÓN Y TRANSMISIÓN DEL PASADO A TRAVÉS DE MICRO-NARRACIONES COTIDIANAS
}

\author{
FRAGMENTED MEMORIES OF THE CHILEAN \\ DICTATORSHIP: CONSTRUCTION AND \\ TRANSMISSION OF THE PAST THROUGH DAILY \\ MICRO-NARRATIONS
}

\author{
Alicia OlIVARI VARGAS* \\ Universidad de Barcelona
}

\begin{abstract}
Resumen: En este artículo se analiza la construcción de sentidos del pasado dictatorial chileno a través de micro-narraciones cotidianas. Se realiza a partir del estudio de tramas de memoria local conformadas en la vida cotidiana de un barrio de Santiago de Chile, dentro de las cuales uno de sus componentes centrales son las micro-narraciones, o lo que ha sido descrito en otros contextos como memorias fragmentadas. El objetivo de este artículo es comprenderlas como forma de memoria y analizar su rol en los procesos de transmisión intergeneracional a nivel local. Con ello, se ponen en tensión aquellos planteamientos que observan la fragmentación desde las dificultades que representa para la comunicación del pasado, en tanto forma que desafía los modos convencionales de narración. Tal como muestra la investigación etnográfica, en el contexto de un territorio cargado históricamente de conflictos, esta forma de memoria tiene especial preeminencia respecto de la constitución de referentes cotidianos que participan de procesos de identificación y arraigo en los jóvenes.
\end{abstract}

\footnotetext{
* Doctora en Sociedad y Cultura: Antropología Social. E-mail: aliciaolivariv@gmail.com. Texto basado en los estudios doctorales financiados por la Corporación Nacional de Ciencias y Tecnología (CONICYT) a través del programa de Becas Chile.
} 
Palabras clave: memoria colectiva, memorias locales, vida cotidiana, fragmentación, transmisión intergeneracional.

Авsтract: This article analyzes the construction of meanings of the Chilean dictatorial past through daily micro-narrations. It is made from the study of local memory frames formed in the everyday life of a neighborhood of Santiago de Chile, within which one of its central components are micro-narrations, or what has been described in other contexts as fragmented memories. The aim of this article is to understand them as a form of memory and analyze their role in the processes of intergenerational transmission on a local level. It puts into tension those approaches that observe fragmentation from the difficulties it represents for the communication of the past, as a form that defies conventional modes of narration. As ethnographic research shows, in the context of a territory historically loaded with conflicts, this form of memory has special preeminence for the constitution of everyday referents that participate in processes of identification and rootedness in young people.

KEYwORds: collective memory, local memories, everyday life, fragmentation, intergenerational transmission.

\section{Introducción}

Un día en medio de una conversación sobre los tiroteos que ocurren en la población y que motivaron la construcción de una estructura de seguridad en la escuela, una vecina comentó: para el pronunciamiento militar si que habian balas y se metían a la casa. En efecto, el sonido de las balas resuena en el barrio con intensidades distintas según el momento. Su frecuencia ha variado a lo largo de los años, pudiéndose contar tanto lapsos de relativa calma como otros de especial tensión, dependiendo de la presencia y actitud de la policía así como de la situación del tráfico, entre otras cosas. ${ }^{1}$ Pero es un sonido conocido en cuanto también se escuchó y sufrió durante la dictadura. Se trata de una problemática actual y pasada, y que sirve como imagen representativa de aquello que se desarrolla en estas páginas: la memoria fragmentada como forma de recuerdo local. Una metáfora de la vinculación entre el pasado dictatorial y el presente

\footnotetext{
1 Muchos vecinos relacionan el inicio de este tipo de problemáticas con las primeras intervenciones estatales desplegadas a partir del año 2001. Allí comienza la era de la intervención en el barrio realizada de manera oficial, explícita y fundada en políticas públicas de gobiernos democráticos. Esto trajo consigo la implementación de programas sociales, así como control, represión y abusos por parte de fuerzas de seguridad.
} 
que se produce a partir de una escena relatada, una breve anécdota, una palabra, un sonido. Los fragmentos, entendidos como micro-narraciones, actúan como conectores entre dos temporalidades conflictivas y significativas en el territorio: pasado reciente (dictadura) y pasado inmediato (intervención). Sin dirección unívoca, los sentidos van y vienen, así como las balas aparecen en el presente y producen recuerdos, su sonido remonta a aquellas pretéritas para ser comparadas con las actuales.

En un contexto nacional en el que los aprendizajes y legados del pasado son todavía objeto de debate público, sostengo que investigar acerca de las expresiones locales y cotidianas de rememoración se vuelve relevante en función de tres consideraciones. En primer lugar, en tanto que las memorias locales han generado menor interés en los estudios y acciones relativas a las memorias de las dictaduras del Cono Sur que las memorias nacionales u oficiales (Jelin y Del Pino, 2003). En segundo término, en la medida que la escala local representa un acercamiento a la expresión particular de ciertas historias narrativas, lugar en el que finalmente se puede comprender su relevancia para personas y comunidades (White, 2000). Por último, porque se trata de un territorio particular en el que el presente adquiere ciertas características que pueden ser determinantes, o al menos influyentes, a la hora de estudiar la transmisión intergeneracional (la vigencia del conflicto y la represión policial, y la urgencia del presente, entre otras).

En este marco, la investigación sobre la cual se basa este texto analizó las memorias construidas en la vida cotidiana de un barrio de Santiago de Chile llamado La Aurora. ${ }^{2}$ El proceso consideró un trabajo de campo etnográfico desarrollado entre los años 2013 y 2015 y fue posible gracias mi participación en un colectivo cultural local. La Aurora corresponde a un territorio considerado emblemático en Chile, carácter vinculado a sus orígenes, su recorrido político y comunitario, así como a su presente estigmatizado e intervenido que ha cargado de emergencias su actual vida cotidiana.

En este territorio se observaron diversos modos a través de los cuales el pasado dictatorial se hace presente cotidianamente, todos los cuales conforman tramas que representan un pasado activo, más vivo de lo que un aparente desinterés demuestra a simple vista. Dentro de estas tramas las memorias fragmentadas

2 Todos los nombres presentes en este artículo, incluido el de la población, son ficticios. Dada la situación actual se busca resguardar y tomar precauciones que eviten contribuir a los procesos de estigmatización que sufre el barrio. 
tendrán preponderancia, lo que instala los objetivos de este artículo, estos son: comprender los fragmentos como un modo de memoria, analizar su papel en los procesos de transmisión y, con ello, poner en tensión los argumentos que las señalan como problemáticas para los mismos. Esta «indagación sobre el fragmento» devela la importancia que tienen estas micro-narraciones para la construcción y transmisión intergeneracional del pasado, en un territorio en el que convive un presente acelerado por las urgencias junto a la presencia de diversos pasados locales.

\section{El fragmento como memoria y la pregunta por la transmisión}

La población La Aurora es considerada un barrio emblemático en el país tanto por su pasado como por su presente. En primer lugar, se considera icónica respecto de su historia fundacional. Tres procesos muy característicos de la formación de barrios populares en el siglo XX dieron vida a un tipo de territorio, una "población», que se llamó La Aurora. ${ }^{3}$ En segundo lugar, incluyo su pasado relativo a la dictadura. Tal como han recogido y relatado diversos libros, textos de divulgación, artículos académicos y material audiovisual, en este lugar se vivió uno de los pocos intentos de resistencia armada al Golpe de Estado. En él convergieron grupos de militantes provenientes de fábricas cercanas y se enfrentaron con policías y militares. Debido, además, a su trayectoria de organización comunitaria y militante en partidos de izquierdas, sus habitantes vivieron duras jornadas de allanamientos y represión. Por último, su carácter emblemático refiere a que ha sido categorizada por las autoridades como «barrio vulnerable» $\mathrm{y}$ «barrio crítico", lo que la ha convertido en objeto predilecto de procesos de intervención estatal desde el año 2001, cuya cara más cruda es la ocupación policial a largo plazo (Han, 2013). Los consecuentes procesos de estigmatización sumados a otras problemáticas como la pobreza, la violencia estructural, la presencia del narcotráfico y las violencias que conlleva, han generado que el presente se cargue de emergencias y acontecimientos que aceleran su vivencia.

En este barrio la dictadura es recordada de diversos modos que incluyen: conmemoraciones organizadas por el partido comunista o colectivos locales

3 Estos procesos incluyen migraciones campo-ciudad, desplazamientos dentro de la capital debido a la crisis habitacional de la época, tomas de sitios y ocupaciones dirigidas por el Estado, entre otras cosas. 
realizadas cada día 11 de septiembre; conmemoraciones insolentes, desarrolladas en la misma fecha; ${ }^{4}$ narraciones oficiales y relatos construidos por organizaciones del barrio, organismos gubernamentales y/o académicos que narran lo sucedido en dictadura y buscan difundirlo en el espacio público; y memorias fragmentadas que emergen en el transcurrir cotidiano de la rutina.

Dentro de este escenario de memorias y actores diversos que conforman tramas locales, un modo adquiere preminencia en la cotidianidad y es la memoria fragmentada. Sobe la base de esta evidencia y considerando las características del territorio, surge la interrogante que guía este texto: ¿cómo opera y qué rol juega este tipo de memoria en términos de la construcción de sentidos del pasado y su transmisión en la vida cotidiana?

Desde niños aprendemos a dar sentido narrativo al mundo que nos rodea, organizar así la experiencia, significarla y ubicarla dentro de un universo de sentido que ha sido colectivamente construido (Gergen, 1994; Bruner, 1995). En este sentido, la narración no corresponde a una forma de organización de la vivencia que el ser humano utiliza como instrumento para comprender el mundo, dentro de otras posibles. Se trata, dice Ricoeur (1987), de la respuesta a una necesidad transcultural de aprehender el carácter temporal de la existencia humana. Una forma de articulación argumentativa que posee un carácter histórico y culturalmente contingente (Gergen, 1994; Bruner, 1995; Cabruja, Vásquez e Î́niguez, 2000). Es así como en nuestras sociedades occidentales y su modo convencional de narrar, la configuración global del relato, o sea la existencia de una trama, tiene un papel clave (Gergen, 1994). Los componentes de un relato permiten la construcción de sentido dado que su significado no se define por su carácter de verdad o falsedad en el contenido, sino que se desprende de la vinculación entre ellos, del lugar que ocupen en la totalidad (Bruner, 1995).

En este marco comprensivo, la fragmentación de las narraciones, y en especial de aquellas que construimos sobre el pasado -ejemplo paradigmático del proceso narrativo de recreación del mundo (Cabruja, Íniguez y Vázquez, 2000)- suele ser analizada como problemática para su comunicación.

4 Las conmemoraciones insolentes se refieren a las hogueras y posteriores enfrentamientos con la policía que se desarrollan cada 11 de septiembre. Al caer la noche se encienden fogatas en las esquinas de la población de las que participan muchos vecinos, se trata de una suerte de tradición en el barrio. A medida que la jornada avanza a ellas se les suman enfrentamientos entre habitantes, en su mayoría jóvenes, con fuerzas de seguridad. Ninguna de estas acciones son convocadas por organizaciones ni actores locales. 
Desde estudios subalternos la noción de fragmento se utiliza para dar cuenta de aquel modo de relato que se levanta con dificultad en los límites de las narraciones oficiales. Una forma de memoria constituida desde un lugar de dominación, marginalidad y deslegitimidad, respecto de quienes escriben la historia y las memorias de una sociedad, comunidad, pueblo, etc. Su estructura parcial, dispersa, vivencial, personal y efímera está indisolublemente ligada al sujeto que narra que no posee recursos ni autoridad para participar de la construcción de las narraciones oficiales y públicas (Das, 1995; Steedly 1993; Ortega, 2008). Por consiguiente, se trata de memorias que se constituyen desde la oposición, no necesariamente como resistencia deliberada de un grupo humano, sino más bien en tanto que efecto de la imposición de relatos oficiales que inevitablemente contienen fisuras. Éstos han pasado por procesos de institucionalización, se han vuelto hegemónicos y alcanzan un mayor grado de coherencia, orden y unicidad que esas «otras» memorias subterráneas (Jelin, 2002; Da Silva Catela, 2003; Pollak, 2006).

La forma parcial, incompleta, «subjetiva» y fragmentaria de estas memorias clandestinas configuran un "punto de vista fugitivo» sobre la realidad histórico social, una mirada compuesta por un conjunto de voces parciales, testimonios locales y personales, indeterminados y que no dependen de un marco interpretativo globalizador para su circulación pues sólo tienen sentido en su ausencia de cierre (Steedly, 1993; Ferrándiz, 2004). Pero estas características también pueden volverse obstáculos en relación a su nivel de alcance o impacto. Esto porque se expresan en relatos individuales «sueltos» que no se integran en uno colectivo y, más bien, representan puntos de vista disgregados que transmiten una experiencia y no una historia construida a partir de ella y vinculada al imaginario colectivo (Pécaut, 2004; Stern, 2000).

De este modo, las memorias fragmentadas parecen tener la particularidad de constituirse como fracciones o retazos. Es decir, hablan no solo de lo que hay contenido en ellas sino también de lo que no está: la totalidad. Se describen desde la carencia de elementos como coherencia, unicidad, generalización, claves de contextualización, politización, estabilidad, etc. Estas ausencias operan como punto de partida y de referencia. En definitiva, estos planteamientos las analizan desde la comparación con aquellas memorias estructuradas y coherentes, de carácter globalizador: las memorias oficiales, institucionalizadas, politizadas. La misma noción de fragmentación, supone un todo que ha sido partido por lo que de él solo quedan los trozos o solo podemos acceder a ellos y no al conjunto. Esto quiere decir que aun cuando la partición no sea pensada necesariamente como 
problemática, subyace la idea de una posible y deseable narrativa que dé cuenta de forma «cabal» del pasado.

En este marco, los fragmentos parecen no lograr una representación del pasado óptima como aquellas de mayor nivel abarcativo. Una dificultad sobre todo si el retazo no va acompañado de un relato colectivo. Pero ¿es la fragmentación necesariamente una amenaza para la construcción narrativa de la memoria y su transmisión? Ante esta interrogación sostengo que lo problemático proviene de la comparación entre formas de recordar y de narrar que trabajan en distintas escalas sin considerar ese factor y sus efectos. Según lo investigado, en la vida cotidiana de la población La Aurora los fragmentos operan como micro-narraciones que sirven tanto para la comunicación de memorias de la dictadura entre sus habitantes como para su apropiación y resignificación por parte de los jóvenes. Si entendemos la transmisión como un proceso dialógico de re-narración, re-contextualización y apropiación por parte de sujetos que no vivieron cierto pasado, que ocurre en diversos ámbitos de la vida social (institucionales y cotidianos) (Berliner, 2005; Sarró, 2007; Welzer, 2008; Achugar et al., 2014). No debe perderse de vista cuando ésta ocurre a nivel local, ordinario, sutil, incluso efímero, sin depender de organizaciones o actores de memoria ni responder a objetivos estratégicos. Y las memorias fragmentadas se vuelven un caso privilegiado para ello, aun cuando el alcance de los sentidos construidos a través de ellas sea limitado. Asimismo, es importante tener en cuenta las condiciones de vida cotidiana puesto que ciertos factores como la continuidad de la represión puede volverse un elemento clave (Cavalcanti, 2003; Crenzel, 2011).

\section{Las formas del fragmento}

Mi hijo tenía como unos 15 años, debe haber tenido porque estaba haciendo la cuestión de la confirmación, y nosotros estábamos en una reunión en la capilla con los otros nińos y el Antonio estaba en la parroquia y estábamos con el cura nosotros acá en la capilla y de repente llegan los chicos de acá de la parroquia corriendo a avisarnos que se habían llevado preso al Antonio. El viejo iba a partir corriendo y el cura le dijo: «no, a ver, espérate». Le dijo: «dime ¿̇tu hijo tiene alguna cuestión policial, que haya caído preso por robo, ficha policial?». "No», le dijo el viejo, «él está estudiando». "Ya», le dijo el cura, «vamos». Y partieron los dos a buscarlo y empezaron a seguir la micro en que lo habían llevado, porque lo llevaron cuando él con sus amigos 
venían saliendo de la parroquia y estaban los milicos ahí, y los paran y los empiezan a revisar, y el Antonio andaba trayendo en los bolsillos una prueba del colegio donde tenía un plano de un motor, porque estaba estudiando mecánica, y entonces los milicos dijeron que ese era un plano para una bomba [ríe] y por eso se lo llevaron. Y el Antonio les decía que no, que eso era un motor, que era una prueba del colegio y que preguntaran al colegio, y no, se lo llevaron no más. Dice el Antonio que los tiraban en el suelo, porque se llevaban a varios chicos, por distintas cosas, y dice que los milicos andaban por encima de ellos, los pisaban y de repente les pegaban con las culatas...y yo ¡uy! esa vez yo me quería morir. Yo decía: «no, si el Antonio no va a llegar vivo, lo van a matar», figúrate, así pensábamos nosotros. Y después como a las dos de la mañana más o menos el cura lo ubicó dónde andaba el autobús, lo habían andado trayendo por todo Santiago, por todo Chile yo creo, y hasta que el cura lo ubicó y ahí se lo entregaron y el cura le dijo a los que lo tenían «este no es un plano de una bomba».5 (Carmen, 2015)

Esta breve historia surge en una conversación con una vecina, cuándo ésta versaba sobre los años posteriores al golpe militar y cómo su familia continuaba participando en las actividades de la parroquia. ${ }^{6}$ Dado el contexto dictatorial, en este tipo de encuentros se solían compartir rumores acerca de la amenaza de allanamientos o detenciones, sobre todo la que se sospechaba pesaría sobre el cura, conocido en ese entonces por su posición contraria al régimen. Sin embargo, lo que sorpresivamente sucedió fue la detención de su hijo. Este fragmento, tal como otros presentes en sus recuerdos, ciertamente tiene un carácter anecdótico en la medida que se relata desde lo inesperado que resultó. De todas formas, esta calidad no implica liviandad porque, en efecto, para Carmen se constituyó en una situación no solo relevante sino que incluso dramática, a pesar de lo cual no es relatada con ese tono enunciativo. Por otra parte, la historia es contada como si no hiciera falta una explicación del contexto trágico que se vivía en la sociedad

\footnotetext{
5 Respecto de algunos términos: «micro» es como se le llama en Chile a los autobuses. En general se aplica para el transporte público, pero a veces también sirve para referirse a vehículos policiales muy similares. "Milicos» se refiere a los militares.

6 Carmen tiene 76 años, nació y ha vivido toda su vida en la población, específicamente en la zona más antigua. Hoy habita junto a una nieta la misma casa en la que vivió con sus padres. No ha militado ni milita en ningún partido político, ni tiene familiares víctimas de la represión política. Participa y ha participado de organizaciones locales como la parroquia, la junta de vecinos y colectivos culturales.
} 
chilena y local. Aunque la mayoría de los medios de comunicación lo ocultaban o reproducían montajes noticiosos, ya se sabía de las muertes y desapariciones. Antonio no era militante de ningún partido político ni participaba de movimientos sociales, fue detenido por ser considerado sospechoso mientras caminaba con un grupo de amigos. Su madre me relata la situación más de 40 años después como un breve relato entre medio de otros en la conversación.

Así, historias sobre situaciones vividas o contadas por vecinos se repiten en las voces de los pobladores. Al preguntar por «la dictadura» aparecen sucesos y experiencias, en su mayoría, cotidianos que conforman micro-narraciones efímeras, escasas de contextualización y peso político-ideológico.

Estos fragmentos representan momentos icónicos que emergen al modo de recuerdos cotidianos y se describen como si fueran comprensibles en y por sí mismos, sin la necesidad de ser situados en un marco narrativo más general. Se cuentan ocasionalmente, suelen involucrar al narrador y su familia, se componen de imágenes fugaces y esporádicas que sintetizan un pasado sobre el cual a primera vista parece haber desinterés (Stewart, 2004). Operan como una especie de zoom en ausencia de una imagen global como antecedente, cuadro que de todas formas puede ser inferido a partir de los sentidos contenidos en el relato. Este tipo de historias se constituyen en ejemplos, pero de un asunto que puede no estar explicitado previamente, ni ser necesariamente configurado a posteriori a modo de conclusión. De este modo, claves enunciativas y comprensivas como podría ser una alusión a los problemas de abastecimiento que se vivían en la época y la escasez de alimentos, son reemplazadas por un relato sobre un vecino dueño de un almacén que regalaba víveres a sus amigos, mientras otros no podían acceder a ellos. Se configura, en definitiva, una pequeña historia en la que sobre una base experiencial concreta, el oyente interpreta según cómo se van desplegando los trozos en el discurso, pero con la libertad que brinda la escasa contextualización o anticipación de los mismos. El fragmento ilustra un fenómeno más amplio o un argumento que se quiere destacar. Un episodio concreto que se encuentra disperso en el devenir de una conversación muestra una realidad, ilumina una situación que podría fácilmente generalizarse, aunque dicho ejercicio no se anuncia. Un ejemplo de ello es el relato presentado al inicio de este apartado. En él, la narradora, a través de la detención de su hijo muestra la amenaza de aprehensión de un familiar o conocido que pesaba sobre la población, así como el peligro que una situación similar terminara en ejecución o desaparición. Esta amenaza opera como un telón de fondo que no es formulado directamente, sino que es algo que se va dibujando a partir de los distintos fragmentos. 
Con frecuencia se utiliza al inicio del relato la palabra «mira» denotando que algo está por mostrarse, como quien indica y anticipa un punto de referencia que carece de más explicación que la simple instrucción a observar. Tampoco hay una definición que venga después, la escena viene y se va sin más, pero siempre incluyendo detalles que permiten ponerse en situación tal como lo hace un cuento creado desde la pura imaginación.

Este carácter ilustrativo no solo se refiere al contenido de lo contado. Los fragmentos también pueden informar acerca de sensaciones, comunicar estados e impresiones describiendo la experiencia consciente del mundo del o la protagonista y no de manera literal. Más que describir ampliamente un suceso y los argumentos de la acción (agente, intención, meta, etc.), pueden constituir también un panorama de conciencia (Bruner, 2004).

Yo salí a comprar a la feria y lo primero que veo, pero yo eso nunca he sabido si lo vi, lo soñé o qué, un tremendo tanque, con un inmenso cañón enfocado para acá, pero yo nunca lo he conversado con otra persona para ver si fue eso, pero era inmenso, un tremendo cañón ¿ंTe figurai uno salir a comprar así? (Carmen, 2014)

En esta breve narración lo significativo no es si efectivamente el hecho ocurrió, si fue un sueño o simplemente una escena producto de su fantasía y del miedo que se imponía y que impregnó su recuerdo. Carmen destaca su impresión y la sensación de extrañeza que produce algo tan extraordinario como encontrarse con un tanque instalado en la rutina misma. Alude a algo que se impone como excepcional e inexplicable, difícil de comprender e insertar en la cotidianidad.

De esta manera, los fragmentos representan un tipo particular de narración de memoria, una micro-narración. La que, a su vez, tiene tres versiones. La primera es el micro-relato cuyo ejemplo fue ya mencionado al comenzar este apartado y se ha descrito hasta aquí.

La segunda versión es la de una imagen más amplia e icónica a nivel local. En la investigación realizada se identificaron dos imágenes emblemáticas que se configuraban en los discursos de los vecinos a partir de memorias fragmentadas, el golpe militar y los allanamientos. Dos fragmentos hechos de fragmentos que surgen como intercalados. Ambos acontecimientos son mencionados de forma 
recurrente tanto dentro de un mismo discurso como de manera transversal por los vecinos. Son escenas que van dando vida a un conjunto como un cuadro hecho en forma de collage de experiencias. Si los fragmentos dispersos antes referidos se constituyen como acotadas y discretas situaciones que sirven en ocasiones para ilustrar un tema, éstos dan vida a una representación mayor. Se produce un dibujo más amplio en la medida que se retorna a él a lo largo de la conversación, para describir una arista o vivencia diferente.

Yo tengo un hermano que él vivió toda la vida en Argentina, de los 23, algo por ahí que tenía él, se fue aquí de Chile, se fue con la mejor disposición, pero la cosa es que después nos vinimos a dar cuenta que él era comunista, cuando ya estuvo afuera porque a nosotros se nos perdió mi hermano un tiempo, se nos perdió de comunicación. Pero, en ese tiempo cuando hubo el Golpe de Estado los dos éramos los más, yo no quise seguir estudiando, yo llegué hasta octavo y me fui a trabajar, y trabajé de aprendiz en una sastrería y ahí estuve, y después yo estaba trabajando allá en la calle Bastidas [zona centro de Santiago] y ese día del Golpe de Estado era yo y mi hermano los que no llegábamos. A mí me vieron como a las cinco de la tarde. Yo tenía 18 años y ya estaba gordita de mi hijo mayor, entonces estaban todos preocupados, todos preocupados, no sabían que pensar, como no podíamos pasar para acá, entonces la micro pasaba por allá por la calle Juan Valdebenito, una micro que nos servía a nosotros que se llamaba la 45 San Esteban, y esa micro yo tomé y no me moví de ahí, dije yo: «aquí me voy a quedar", y nos dieron las cinco de la tarde y la micro lo desviaban hacia Recoleta [comuna en la zona norte] hacia allá, hacia allá, hasta que de repente agarró vuelo y se dio unas vueltas por unas calles y llegamos aquí, yo llegué a las cinco de la tarde a mi casa y mi hermano llegó a las seis, pero después con los años supimos que mi hermano llegó a las seis porque estaba en una parte, como en una sala u oficina quemando y cortando papeles que eran del partido. (Lidia, 2015).

La descripción de cómo llegó a su casa el 11 de septiembre de 1973 marca una especie de desvío en el discurso de Lidia que trataba sobre la posición política 
de su familia y, en particular, de su hermano de quien no se conocía militancia. ${ }^{7}$ $\mathrm{Al}$ iniciar la conversación, Lidia explica que en su familia no se solía hablar de política ni se les permitía a los hijos e hijas participar. Por lo mismo, ella no se definía como comunista, por desconocimiento, aunque simpatizaba con las causas y ganas no le faltaban. Más tarde, supo que en su familia efectivamente había cercanía con la izquierda y que su hermano, en particular, militaba. En ese marco, el relato de lo que sucedió ese día es breve, pero detallado. Y más adelante en la entrevista volverá a surgir para recordar cómo su madre le advirtió por la mañana que no saliera, una instrucción que Lidia no acató. Con esta nueva referencia, vuelve a recordar todo lo que le costó regresar a la población por lo difícil que resultaba cruzar la principal arteria de la ciudad y el miedo que significaba un recorrido lleno de obstáculos y desvíos obligados bajo intimidación por parte de los militares.

El día 11 de septiembre, el "golpe», aparece en distintos momentos para rememorar diferentes ángulos y pequeños eventos que tuvieron lugar en su transcurso. Una jornada histórica para el país que se configura a través de una suma de relatos sobre sucesos inesperados narrados desde una perspectiva cotidiana y local. Se describe como una interrupción de aquello que representa de forma paradigmática el devenir de la rutina: el regreso a casa. Desde la ruptura de lo ordinario, se muestra la forma en que se hizo excepcional un día cualquiera en que el tránsito se volvió imposible. El Golpe de Estado se narra desde la experiencia que se desarrolla, qué hacían, cómo eso se vio perturbado y cómo se resolvió. Así, la imagen que se conforma no corresponde a aquella representada en los relatos oficiales graficada, por ejemplo, en el bombardeo a La Moneda o la muerte del presidente Allende. Más bien se trata de una composición constituida desde la localidad del territorio y los momentos vividos dentro del paso de la jornada. Lo mismo sucede con los allanamientos que se sufrieron de manera masiva.

Por último, identifico una tercera versión de los fragmentos sobre el pasado dictatorial. Se trata ya no de un relato, sino un comentario, una anécdota en su mínima expresión. Son frases «sueltas» que se lanzan al pasar en una conversación o un encuentro furtivo. Emergen en medio del habitar y el transitar cotidiano,

7 Lidia tiene 62 años, nació en La Aurora y ha vivido toda su vida allí. Hoy vive junto a uno de sus hijos en una casa en la tercera zona que ha configurado históricamente el barrio, a pocos metros de la que fuera la casa de sus padres y que hoy habita una hermana. No milita ni ha militado en partidos políticos, sí participa de organizaciones locales y trabaja actualmente en el centro de salud primaria del barrio. Su hermano fue exiliado durante la dictadura. 
y de manera fugaz hablan sobre lo vivido, tal como recuerda una vecina espontáneamente: nosotros nos despertamos en la mañana y el viejo fue a salir a comprar el pan... y estaban ahi los milicos, todos.

Con una frase «simple» como ésta, nuevamente nos situamos en la vida cotidiana, en la actividad diaria. Y la excepcionalidad se asienta allí a través de la presencia militar. A través de escasas palabras se instala un estado de cosas que vino a perturbar la tranquilidad y seguridad que otorga la repetición de la rutina, una situación que pasará a operar como telón de fondo para el resto de la conversación o interacción mientras se despliegue. Corresponden a alusiones rápidas y concisas que pueden no tener respuesta por parte del otro presente. Es lo que me sucedió alguna vez mientras esperaba para comprar pan una tarde en un almacén. Por su concurrencia se formó una pequeña cola de tres personas que esperábamos el turno: $y$ eso que no estamos en la UP!, ${ }^{8}$ exclamó sonriendo una vecina al entrar.

\section{Micro-narraciones que son presente y referente}

Yo crecí con esos relatos, crecí como viviendo esos espacios, y aparte que me permiten entre comillas como asimilar ciertas cosas, un ejemplo, como cuando mi papá me decía, o mi mamá me decía: «no es que aquí por afuera pasaban las tanquetas» y digo: «puta ahora pasa el gope» [sonríe]. Y no lo veo tan diferente, no lo veo tan diferente, mi mamá me dice: «antes no se podía hablar con cualquier persona, porque cualquier vecino podía ser sapo" y yo le digo: «ya jahora me pasa exactamente lo mismo!», cualquier persona con la que puedes hablar cualquier tema te puede estar sapeando respecto a algo, así que no veo como un pasado dictatorial sino que lo asimilo como a un presente dictatorial, la persona es distinta, quizás como la figura es distinta, quizás un poco el escenario puede ser un poco distinto, pero la trama es la misma, los problemas son iguales, veo los mismos conflictos que mis papás vieron hace tiempo. ${ }^{9}$ (Gabriel, 2015)

8 Esta frase alude al periodo de la Unidad Popular, mientras gobernaba Allende, cuando se sufrían problemas de abastecimiento y eran frecuentes las largas colas para conseguir alimentos.

9 Sobre algunos términos: las «tanquetas» corresponden a tanques de guerra de menor tamańo utilizados para la ocupación militar desplegada en dictadura. La sigla «GOPE» se refiere al grupo de fuerzas especiales de la policía chilena, pero en la población se utiliza para 
El caso de Gabriel es particular ya que se trata de un joven cuya vida, como él mismo refiere, ha estado llena de pasado. ${ }^{10} \mathrm{Ha}$ sido socializado políticamente y rodeado de historias sobre la dictadura. Aun así, el papel que devela sobre los fragmentos para la transmisión intergeneracional también se ve en otros jóvenes, incluso en aquellos que describen no saber nada sobre ese pasado. En éstos últimos si bien las narraciones son más escasas, al igual que el conocimiento sobre lo sucedido, los fragmentos aparecen para servir de referencia o contraste con el presente.

En este sentido, lo significativo para el análisis no es que las micro-narraciones coincidan o se opongan directamente con otras versiones. Es, más bien, que se trata de un tipo de rememoración, quizás uno de los más apegados a la cotidianidad, que puede permitir procesos de comunicación intergeneracional. Como sostiene Da Silva Catela (2003: 21), los vecinos y sus micro-narraciones «no niegan esta memoria oficial, ni la desconocen, pero tampoco la reproducen sin críticas. Ellos cuentan "su experiencia", hablan de sus fechas y reconstruyen sus recuerdos con elementos que fundamentalmente otorgan sentido a su comunidad identitaria, aspectos cotidianos del momento». En efecto, micro-relatos, imágenes y anécdotas pueden constituirse en puntos de referencia e identificación para los habitantes del barrio que no vivieron ese pasado. Muchas veces estas memorias configuran o implican un colectivo, suponen tácitamente un «nosotros» que posee vivencias similares y, al mismo tiempo, sirven como elemento de arraigo al territorio.

Resulta innegable que los sentidos del pasado contenidos en las micro-narraciones, cuya trama puede estar casi ausente al igual que su capacidad integradora y sus claves de comprensión global, producen un alcance que será reducido en tiempo y en espacio. Operarán en una escala micro, cotidiana y anclada al territorio. Esta afirmación adquiere más peso si comparamos este tipo de memoria con lo que suele ser considerado como su contraparte, los relatos oficiales o institucionalizados. Éstos, en tanto que compuestos de una estructura y una trama clara y coherente, se erigirán en relación y proporción a la sociedad y respecto de

identificar un jeep policial blindado que suele rondar por sus calles. La palabra «sapo» se utiliza para designar a quien es considerado un delator.

10 Gabriel tiene 24 años, es nacido en la población y actual habitante. Hasta hace pocos años militaba en las juventudes del Partido Comunista, pero decidió retirarse por diferencias con la dirección. Hoy participa de colectivos culturales locales. En su familia diversos miembros han sido militantes de partidos políticos y movimientos de izquierdas, razón por la que algunos fueron víctimas de represión y exiliados durante la dictadura. 
un mayor lapso de tiempo. Pero desde el argumento desarrollado en este artículo estas consideraciones no son incluidas para asumir en la memoria fragmentada una merma en su capacidad de crear y transmitir sentidos del pasado, producida por su carácter localizado y experiencial que trabaja a pequeña escala. Más bien tiene como propósito afirmar su diferencia. Esto porque, parafraseando a Stewart (2004), asumo que más allá de grandes discursos o relatos históricos sobre la dictadura que aleccionan y transmiten conocimiento, la vida cotidiana puede transcurrir, sobre todo en la caso de jóvenes que no lo vivieron, con apenas un reconocimiento pasajero de eso que afectó a un país entero. Lo cual no quiere decir que el pasado esté ausente, así como tampoco que sea imposible la constitución de una conciencia histórica que no deba su origen a prácticas convencionalmente semánticas. Cuando un joven de La Aurora enuncia sin preámbulos: la policía nos reprime igual como lo hacian en dictadura, nos han reprimido siempre, establece un vínculo directo e inapelable con el pasado que no requiere de mayor contextualización ya que para él lo que importa y apremia, es el hecho presente. Lo que está en juego es que muy probablemente ese joven nacido en democracia haya crecido rodeado de policías como habitante de un territorio ocupado y, no tanto, la continuidad, el puente, que esté estableciendo con un pasado condensado en una violencia ejercida hoy sobre su barrio. Pone su experiencia en relación con lo que experimentaron sus padres o vecinos, que ha sido relatado de manera discreta, y ese nexo vivencial es lo que se subraya en un tiempo y espacio cotidiano. Allí, pasado y presente se sintetizan y las claves interpretativas de carácter global poco se extrañan. El pasado parece no importar en forma de pasado sacralizado y estático, sino en la conjunción con la actualidad, porque, como dice Gabriel, el pasado se está transformando en presente. En este sentido, el hecho que estos fragmentos queden restringidos a una circulación en lo habitual del ámbito familiar o vecinal se vuelve una oportunidad para que desde esa proximidad los jóvenes se apropien del pasado y lo re-signifiquen. Y para ello resulta útil la apertura interpretativa que poseen. Y todo esto adquiere más relevancia si consideramos, además, que como en toda narración los fragmentos no solo hacen presente una ausencia (Gianinni, 1987), sino también vinculan pasado y futuro. Instalan señalamientos en el presente que servirán para crear expectativas, abrir o cerrar posibilidades de acción, sentir, reflexionar o no hacerlo (Gergen, 1994; Jelin, 2002; Ricoeur, 2003). 


\section{Conclusiones}

En un barrio que históricamente ha sabido tanto de organización comunitaria y política como de conflictos, el pasado dictatorial se recuerda de manera cotidiana de modos diversos. Todos los cuales conforman tramas de memoria local en las cuales es posible observar continuidades, mutaciones y resignificaciones entre pasados y presentes. Dentro de estas tramas aquellas memorias que se han identificado como fragmentadas tienen un papel clave basado principalmente en su carácter cotidiano. Se trata de una relevancia que puede quedar oculta en tanto aquellas características que las distinguen y facilitan su re-apropiación (su carácter experiencial, local, fugaz, «suelto», etc.), al mismo tiempo parecen desvestirlas de una identificación clara y directa con el pasado.

Estos fragmentos tienen tres formas: el micro-relato, la imagen más amplia y el comentario al pasar. En estas diferentes versiones se constituyen como micronarraciones de memoria en tanto construyen y trasmiten sentidos del pasado, aun cuando muchas veces se encuentran desprovistos de una trama narrativa al modo convencional. Su carácter apegado a la vivencia en el territorio si bien puede implicar un nivel de impacto restringido, al mismo tiempo permite la configuración de una suerte de trasfondo experiencial local que se encuentra latente y aparece a través de situaciones como: una bala, la presencia policial, una emergencia, una palabra, un vecino conocido, etc. Al hacerlo, las micronarraciones, por efímeras que sean, sirven de referentes para los jóvenes ya que son parte del intercambio generacional en su socialización. Gracias a ello, pueden reconocerse y enfrentar asuntos actuales como la intervención, la estigmatización, los abusos policiales, entre otras cosas. Y es que finalmente muchos de estos fragmentos apelan a identidades territoriales y comunitarias más que una identificación militante u obrera. La experiencia y la localidad entonces hacen posible comparar pasado y presente, y hacerlos significativos a ambos. Pero además, la constitución de estos puntos referencia y su apropiación por parte de nuevas generaciones propician procesos de pertenencia y arraigo a la comunidad. Ello, en un contexto de proximidad en el que los vínculos familiares y vecinales son protagonistas y favorecen la comunicación y circulación de estas historias. Por último, los fragmentos al ser parte de tramas locales dialogan con otras memorias. Pueden tomar elementos de las memorias oficiales, así como hacerse parte de las conmemoraciones, sean institucionales o insolentes. En esa flexibilidad y apertura parecen ser más aprehensibles por parte de los jóvenes. 
De esta manera, el trabajo que realizan las micro-narraciones no puede aislarse de la existencia de otros tipos de memoria. Ciertamente en ausencia de relatos históricos y memorias emblemáticas o institucionales, los fragmentos pueden tener un alcance restringido. Sin embargo, esta supuesta dificultad habla de la necesidad de la existencia de redes de memorias, de modos diversos de rememoración y no tanto de una problemática necesariamente asociada a la fragmentación. Su existencia y preponderancia habla más bien de la necesidad de considerar las diferentes escalas en las que trabajan las memorias y tener en cuenta aquella local como un eslabón analítico importante que puede quedar olvidado entre memorias personales y nacionales.

\section{Bibliografía}

Achugar, M.; Fernández, A.; Morales, N. (2014). "La dictadura uruguaya en la cultura popular: recontextualizaciones de "A redoblar"». Discurso y Sociedad, vol. 8, núm. 1, pp. 83-108.

Berliner, D. (2005). «An "Impossible" Transmission: Youth Religious Memories in Guinea-Conakry». American Ethnologist, vol. 32, núm. 4, pp. 576-592.

Bruner, J. (1995). Actos de significado. Más allá de la revolución cognitiva, Madrid: Alianza.

Cabruja, T., Íñiguez, L. y VÁzquez, F. (2000). «Cómo construimos el mundo: relativismo, espacios de relación y narratividad». Anàlisi, núm. 25, pp. 61-94.

Cavalcanti, M. (2003). «Memoria y cotidianidad de la represión en Morro do Borel». En E. Jelin y P. Del Pino (comps.). Luchas locales, comunidades e identidades, Madrid: Siglo XXI, pp. 175-208.

Crenzel, E. (2011). «La transmisión interrogada. Jóvenes, conocimiento y memoria de la represión en el Hospital Posadas, Buenos Aires, Argentina». Universitas Humanistica, núm. 72, pp. 111-132.

DAs, V. (1995). Critical events: an anthropological perspective on contemporary India, Delhi: Oxford University Press.

Da Silva Catela, L. (2003). «Apagón en el Ingenio, escrache en el Museo. Tensiones $\mathrm{y}$ disputas entre memorias locales y memorias oficiales en torno a un episodio de 
represión de 1976». En P. del Pino y E. Jelin (comps.). Luchas locales, comunidades e identidades, Madrid y Buenos Aires: Siglo XXI, pp. 63-106.

Del Pino, P. y Jelin, E. (comps.) (2003). Luchas locales, comunidades e identidades, Madrid y Buenos Aires: Siglo XXI.

FerRÁNDIZ, F. (2004). «Memorias afligidas. Historias orales y corpóreas de la violencia urbana en Venezuela». Historia, Antropología y fuentes orales (HAFO), vol. 1, núm. 31, pp. 5-27.

Gergen, K. (1994). Realidades y relaciones. Aproximaciones al construccionismo social, Barcelona: Paidós.

Giannini, H. (1987). La «reflexión» cotidiana. Hacia una arqueología de la experiencia, Santiago de Chile: Universitaria.

Han, C. (2013). «A long-term occupation: police and the figures of the stranger». Social Anthropology, vol. 21, núm. 3, pp. 378-384.

Jelin, E. (2002). Los trabajos de la memoria, Buenos Aires: Siglo XXI Editores.

Ortega, F. (2008). «Rehabilitar la cotidianidad». En F. Ortega (ed.). Veena Das: Sujetos del dolor, agentes de dignidad, Bogotá: Pontificia Universidad Javeriana, Instituto Pensar, pp. 15-70.

PÉCAUt, D. (1997). «De la violencia banalizada al terror: el caso colombiano». Controversia, núm. 71, pp. 9-31.

Pollak, M. (2006). Memoria, olvido, silencio. La producción social de identidades frente a situaciones limite, Buenos Aires: Al Margen.

Portelli, A. (2013). «Luto, sentido común, mito y política en la memoria de la masacre de Civitella Val di Chiana (Toscana, 29 de junio de 1944)» (Trad. Virginia Sampietro y Lucía Abbattista). Aletheia, vol. 4, núm. 7. Recuperado de http:// www.aletheia.fahce.unlp.edu.ar/numeros/numero-7/traducciones/luto-sentidocomun-mito-y-politica-en-la-memoria-de-la-masacre-de-civitella-val-di-chianatoscana-29-de-junio-de-1944 [Consultado el 23/05/2019]

Ricoeur, P. (1987). Tiempo y narración I. Configuración del tiempo en el relato histórico, Madrid: Ediciones Cristianidad.

Ricoeur, P. (2003). La memoria, la historia, el olvido, Madrid: Trotta. 
SARRó, R. (2007). «Cómo los pueblos sin religión aprenden que ya tenían religión: notas desde la costa occidental africana». Quaderns de l'Institut Català d'Antropologia, núm. 23, pp. 103-122.

Steedly, M. (1993). Hanging without a rope: Narrative experience in colonial and postcolonial Karoland, Princeton: Princeton University Press.

STERN, S. (2000). «De la memoria suelta a la memoria emblemática: hacia el recordar y el olvidar como proceso histórico». En M. Olguín (ed.). Memoria para un nuevo siglo. Chile, miradas a la segunda mitad del siglo XX, Santiago de Chile: LOM.

Stewart, M. (2004). «Remembering without Commemoration: The Mnemonics and Politics of Holocaust Memories among European Roma». The Journal of the Royal Anthropological Institute, vol. 10, núm. 3, pp. 561-582.

Welzer, H. (2008). "Collateral Damage of History Education: National Socialism and the Holocaust in german family memory». Social Research: An International Quarterly, vol. 7, núm. 1, pp. 287-314.

Recibido: $17 / 05 / 2019$

Aceptado: 22/10/2019

\section{(c)}

ENDOXA está bajo una licencia de Creative Commons Reconocimiento-NoComercial-SinObraDerivada 4.0 Internacional 
